\title{
The Expression of Matrix Metalloproteinase-12 by Oligodendrocytes Regulates Their Maturation and Morphological Differentiation
}

\author{
Peter H. Larsen and V. Wee Yong \\ Departments of Oncology and Clinical Neurosciences, University of Calgary, Calgary, Alberta T2N 4N1, Canada
}

\begin{abstract}
Matrix metalloproteinases (MMPs) have important roles in many processes of the developing CNS requiring proteolytic activity such as the migration of neuronal precursors, axonal outgrowth, and vascularization. Another developmental event involving proteolysis is myelin formation, whereby the extensive processes elaborated from oligodendrocytes (OLs) enwrap axons. Here we find MMP-12 transcripts to be produced by OLs in much higher levels than other MMP members examined. MMP-12 activity correlated with the ability of OLs to extend processes in vitro, suggesting a role for MMP-12 in the morphological differentiation of OLs. This was corroborated by results that OL lineage cells from MMP-12 null mice were retarded in their ability to differentiate morphologically and that this deficiency was overcome by the exogenous addition of active MMP-12. Finally, the maturation of oligodendrocyte precursor cells (OPCs) to OLs was significantly reduced in cultures from MMP-12 null mice compared with wild-type controls. We conclude that OL lineage cells express MMP-12 during their maturation and that MMP-12 activity has functional involvement both in maturation of OPCs and in the ability of OPCs and OLs to extend processes.
\end{abstract}

Key words: matrix metalloproteinase; oligodendrocyte; differentiation; myelin formation; process extension; development

\section{Introduction}

The levels of several matrix metalloproteinases (MMPs) are increased in pathology, including tumorigenesis, stroke, multiple sclerosis (MS), and inflammation in which they are thought to have detrimental effects. Hardly appreciated is that such MMP expression may serve beneficial functions. We demonstrated that the elevation of MMP-9 after a demyelinating injury to the adult spinal cord is required for subsequent remyelination by virtue of removing the NG2 proteoglycan that inhibited the maturation of oligodendrocyte precursor cells (OPCs) (Larsen et al., 2003). MMP activity is required for neurite extension (Zuo et al., 1998; Webber et al., 2002) in which the mechanism may similarly involve the MMP-mediated degradation of inhibitory proteoglycans (Zuo et al., 1998). Further supporting the concept of beneficial properties of MMPs is the knowledge that many MMP members are elevated during CNS development (Canete Soler et al., 1995a,b; Vaillant et al., 1999; Sekine-Aizawa et al., 2001). Understanding the role of these proteases during development may shed light on the beneficial components of MMPs required to achieve recovery from pathological conditions.

Previous studies from our laboratory have implicated MMPs

Received April 29, 2004; accepted June 22, 2004.

This study was funded by an operating grant from the Multiple Sclerosis Society of Canada.P.H.L. was supported by studentships from the Alberta Heritage Foundation for Medical Research and the Multiple Sclerosis Society of Canada.

Correspondence should be addressed to Dr. V. Wee Yong, University of Calgary, 3330 Hospital Drive, Calgary, Alberta T2N 4N1, Canada. E-mail: vyong@ucalgary.ca.

DOI:10.1523/JNEUROSCI.2092-04.2004

Copyright $\odot 2004$ Society for Neuroscience $\quad$ 0270-6474/04/247597-07\$15.00/0 in the biology of oligodendrocytes (OLs), which are the cells that extend processes in the CNS to contact axons to form myelin. MMP-9 was found to mediate OL process extension in vitro, and MMP-9 expression correlated with myelination in vivo (Uhm et al., 1998; Oh et al., 1999). In correspondence, MMP-9 removed injury-induced deposition of inhibitory NG2 proteoglycan to allow OPCs to mature into myelinating OLs (Larsen et al., 2003). Because the MMPs are a large group of proteinases capable of processing similar substrates, we asked the question of whether other MMP members might be playing a role in OL biology in addition to MMP-9.

The current study focuses on MMP-12 and its role in OL biology. MMP-12, also known as macrophage metalloelastase, has most often been studied in vascular diseases and lung inflammation in which an increase in MMP-12 has been associated with disease progression (Matsumoto et al., 1998; Annabi et al., 2002). MMP-12 has also been shown to play a role in macrophage infiltration after emphysema (Shipley et al., 1996) and leukocyte and eosinophil recruitment to the lung (Lanone et al., 2002). With respect to the CNS, the literature on MMP-12 is sparse. A study by Vos et al. (2003) reported that MMP-12 is present in active MS lesions in which its expression could be localized to phagocytic macrophages. Although these studies indicate that cells of monocytoid lineage (i.e., macrophages and microglia) are responsible for MMP-12 expression, we demonstrate here that OLs express this protein in large amounts. Furthermore, we show that MMP-12 has functional roles for both the maturation and morphological differentiation (process extension) of cells of the OL lineage. 


\section{Materials and Methods}

Establishment of cultures of OLs, astrocytes, and microglia. For most experiments, mouse OLs obtained from 3-week-old 129/SvEv wild-type or MMP-12 null mice were used. In the series involving various monoclonal antibodies to MMP-12 (see Figs. 3, 4), human OLs were used because these MMP-12 antibodies were generated to human determinants and their cross-reactivity to murine cells was unclear. Human OLs were derived from surgical resection of adult intractable epilepsies; tissue samples contained areas adjacent to, but not containing, the epileptic focus.

For murine and human samples, OLs were purified as described previously (Oh et al., 1999). Briefly, cells were dissociated by trypsin digestion and isolated by Percoll density centrifugation. The initial cell isolates were plated in T-25 $\mathrm{cm}^{2}$ flasks overnight. The floating cells (OLs) were then isolated and plated onto poly-L-ornithine-coated 16-well Lab-Tek chamber slides (Nunc, Naperville, IL) or in six-well chambers. OLs were maintained in Minimal Essential Medium (MEM) containing 5\% fetal calf serum, $0.1 \%$ dextrose, $10 \mu \mathrm{m}$ glutamine, and $1 \mathrm{~mm}$ sodium pyruvate. Using this protocol, the purity of adult human OLs was routinely in excess of $90 \%$ as determined using an antibody (O1 antibody) (Sommer and Schachner, 1981) and immunohistochemistry to an OL-specific glycolipid, galactocerebroside. The purity of mouse OLs was between 80 and $90 \%$.

We reported previously that human OLs initiated processes very slowly in culture in comparison to the robust growth properties of murine OLs (Yong et al., 1991; Oh et al., 1999). Thus, to determine whether process extension from the human OLs could be blocked by MMP-12 antibodies, cells were treated with phorbol-12-myristate-13-acetate (PMA) (10 ng/ml) to initiate OL process extension. In parallel, mouse OLs were similarly treated with PMA for the RNase protection assay (RPA) experiments (see Figs. 1, 2).

Neonatal mouse astrocytes were obtained as described previously (Corley et al., 2001). In brief, brain tissues were dissociated using trypsin digestion and then seeded into poly-L-ornithine $(10 \mu \mathrm{g} / \mathrm{ml})$-coated 100 $\mathrm{mm}$ culture dishes at an approximate density of $5 \times 10^{6}$ per dish. After $7-10 \mathrm{~d}$, which provided for a rapid expansion of the astrocyte population, the purity of astrocytes was assessed to be over $95 \%$ as determined using an antibody to glial fibrillary acidic protein.

Neonatal mouse microglia were isolated similarly to the OLs described above. However, microglia attached to the flasks unlike the floating OLs, and they were purified by the removal of other (floating) cells. The purity of mouse microglia as determined by immunohistochemistry to ionized calcium-binding adaptor molecule 1 (IBA1) (Chemicon, Temecula, CA) is routinely in excess of $90 \%$.

OPC purification. Mouse OPCs were purified by immunomagnetic sorting using the A2B5 antibody and a secondary IgM antibody linked to magnetic beads (MACS; Miltenyi Biotech, Auburn, CA). Briefly, brains were removed from 3 -d-old $129 / \mathrm{SvEv}$ mice, and the cells were dissociated by $0.25 \%$ trypsin treatment $(20 \mathrm{~min})$. The cells were then separated from debris using Percoll density centrifugation (Oh et al., 1999) and incubated with the A2B5 monoclonal antibody (Eisenbarth et al., 1979) for 1 $\mathrm{hr}$ at $4^{\circ} \mathrm{C}$, followed by incubation with bead-coated anti-mouse IgM for $30 \mathrm{~min}$ at $4^{\circ} \mathrm{C}$. Finally, the cells were purified by magnetic sorting according to the instructions of the manufacturer.

OPCs were also cultured from MMP-12 null mice (Shipley et al., 1996) obtained from Dr. Steve Shapiro (Harvard Medical School, Boston, MA). These were similarly isolated on the 129/SvEv background.

OPC maturation and differentiation assay. Purified OPCs from wildtype or MMP-12 null mice were plated onto 16-well Lab-Tek chamber slides coated with poly-L-ornithine at a density of 50,000 cells per well. After cell plating, the A2B5 precursors were allowed to mature for $48 \mathrm{hr}$ at $37^{\circ} \mathrm{C}$ in a $5 \% \mathrm{CO}_{2}$ environment. Feeding medium consisted of an OPC differentiation medium (DMEM-F-12) containing N2 supplement (Invitrogen, San Diego, CA), $100 \mu \mathrm{g} / \mathrm{ml}$ bovine serum albumin, $30 \mathrm{ng} / \mathrm{ml} \mathrm{T}_{3}$ (triiodothyronine), $30 \mathrm{ng} / \mathrm{ml} \mathrm{T}_{4}$ (thyroxine), $10 \mathrm{~nm} \mathrm{D-biotin,} 10 \mathrm{ng} / \mathrm{ml}$ platelet-derived growth factor, and $0.5 \%$ fetal calf serum (FCS). The number of galactocerebroside-positive OLs (Oh et al., 1999) present after $48 \mathrm{hr}$ in each condition was obtained by counting the total number of labeled $\left(\mathrm{Ol}^{+}\right)$cells within each well $(n=4$ wells per condition in each experiment; experiments were repeated three times). To assess whether there still were similar numbers of cells after $48 \mathrm{hr}$ of culture for both genotypes, the total number of cells was counted from eight random fields using Hoechst dye as a nuclear marker.

We also assessed whether OPCs and OLs from wild-type and MMP-12 null mice were morphologically different. Cells were labeled with Ranscht mouse monoclonal antibody (RmAb) (Ranscht et al., 1982; Bansal et al., 1989), which detects both immature and mature cells of the OL lineage. This allowed for characterization of OPCs and OLs at different stages of process extension. Cells were scored using four different morphological classes (see Fig. 6), as follows: low, in which an RmAb-positive cell has few or short processes radiating from soma; low-med (medium), whereby a cell has three to six processes up to a length of three cell soma with minimal interconnection; med-high, indicating a cell with over six processes longer than three cell soma with clear interconnections; and high, whereby there are many processes with extensive interconnections all extending far from the cell soma in all directions. These studies were conducted by counting the entire well of three wells per condition in each experiment; experiments were repeated three times. All morphological examinations were performed under blinded conditions.

Process elongation from human OLs. Purified adult human OLs were used to investigate process extension in the presence of monoclonal antibodies raised to different human MMP-12 domains (all from Chemicon). OLs were treated with antibodies $(10 \mu \mathrm{g} / \mathrm{ml})$ to the N-terminal catalytic (N-term), propeptide, C-terminal (C-term), or hinge regions (Chemicon). MMP-12 proenzyme $(54 \mathrm{kDa})$ is released extracellularly from cells and consists of four domains (propeptide, catalytic, hinge, and $\mathrm{C}$-terminal). The activation process involves the removal of the propeptide, rendering an intermediate form (Inter) $(45 \mathrm{kDa})$. The C-terminal domain is then cleaved by autocatalysis leaving fully active MMP-12 $(\sim 22 \mathrm{kDa})$ consisting only of the catalytic N-terminal domain and part of the hinge domain. A function-blocking antibody to MMP-9 (Cambio, Cambridge, UK) was used in one set of experiments.

Human OLs were first treated with individual antibodies, and process outgrowth was stimulated with PMA $(10 \mathrm{ng} / \mathrm{ml}) 3 \mathrm{hr}$ later. As noted previously, rodent OLs can extend processes readily, whereas human OLs require PMA treatment to prompt their morphological differentiation. Process extension was analyzed after $48 \mathrm{hr}$ in culture by counting the percentage of OLs with processes extended more than three cell soma in length. Five views using a $40 \times$ microscope objective were analyzed for each well in three separate wells for each condition. Experiments were repeated three times.

$R P A$. RNA from purified murine OLs was obtained by applying $1 \mathrm{ml}$ of Trizol reagent (Invitrogen) to each well. Total RNA was extracted according to the instructions of the manufacturer, and $10 \mu \mathrm{g}$ were used for each lane. To analyze the expression of various MMP transcripts, we used a mouse MMP multiprobe set courtesy of Dr. Iain Campbell (Scripps Research Institute, La Jolla, CA) (Pagenstecher et al., 1998). RPA was performed as described by the manufacturer (PharMingen, San Diego, CA). In brief, RNA samples were hybridized to radioactive ( $\left.\alpha-{ }^{33} \mathrm{P}-\mathrm{UTP}\right)$ labeled antisense probe overnight at $56^{\circ} \mathrm{C}$. After $1.5 \mathrm{hr}$ of digestion of unhybridized probe with an RNase A and T1 mix (PharMingen), the protected fragments were treated with proteinase $\mathrm{K}(10 \mathrm{mg} / \mathrm{ml})$ and extracted with phenol-chloroform. Samples were separated on a $6 \%$ polyacrylamide gel and analyzed by phosphor imaging (Molecular Dynamics, Sunnyvale, CA).

Casein zymography of conditioned medium from peritoneal macrophages. Peritoneal macrophages were obtained from mice that had been injected with $1 \mathrm{ml}$ of $3 \%$ thioglycollate medium (Sigma, St. Louis, MO) into the peritoneum. After $3 \mathrm{~d}$, mice were killed and immediately injected with $7 \mathrm{ml}$ of MEM containing 5\% FCS into the peritoneum. The medium now containing macrophages was recovered from the peritoneum and plated in a $100 \mathrm{~mm}$ dish. Macrophages from five animals were pooled for this experiment. Once the cells attached onto the culture dish, the medium was changed to MEM containing 0.5\% FCS and N2 supplement (Invitrogen). The cells were stimulated with lipopolysaccharide (500 ng/ $\mathrm{ml}$ ) and incubated for $48 \mathrm{hr}$.

Conditioned medium was collected from cultured peritoneal macrophages from either wild-type or MMP-12 null mice. The medium was concentrated 100 times (Centricon; Millipore, Bedford, MA), and sam- 


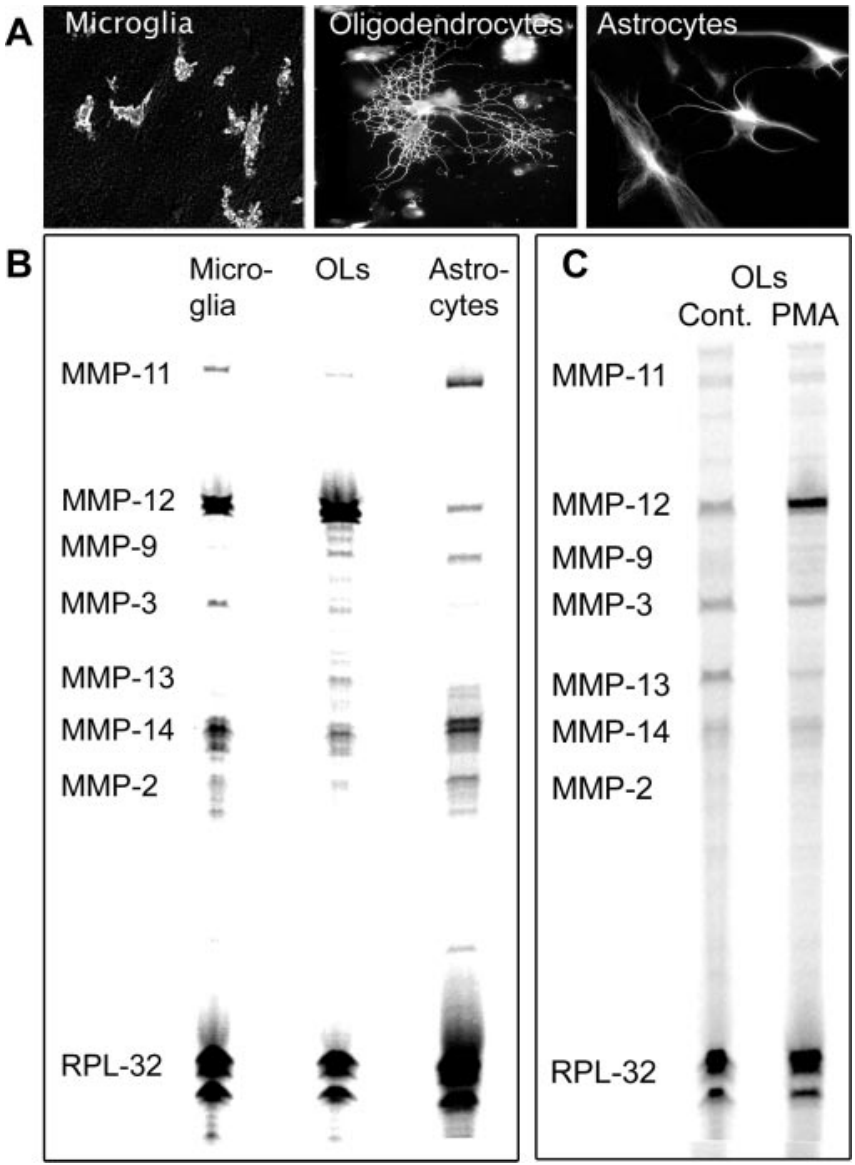

Figure 1. MMP profile in murine CNS cells. Of nine MMP members detected by RPA, cultured murine microglia, $0 \mathrm{LS}$, and astrocytes ( $A$, visualized by IBA1, 01 , and GFAP immunocytochemistry, respectively) show expression of seven MMPs $(B)$. Two other MMPs, MMP-7 and MMP-10, were not detected in any of the cultures. MMP-12 expression was detected in high amounts in murine $\mathrm{OLS}(B)$, and its expression in murine $\mathrm{OLs}$ is enhanced by stimulation with PMA (C). The ribosomal protein L-32 (RPL-32) was used as a housekeeping gene. In C, the increase from control (Cont.) of MMP-12 (relative to L-32) after stimulation with PMA was determined by gel densitometry to be $67 \%$.

ples were separated on a $12 \%$ SDS-polyacrylamide gel containing 1 $\mathrm{mg} / \mathrm{ml}$ casein (Worthington, Lakewood, NJ). After separation, the gel was incubated for $6 \mathrm{hr}$ on a shaker at room temperature with rinse buffer (2.5\% Triton X-100, $50 \mathrm{~mm}$ Tris- $\mathrm{HCl}, \mathrm{pH} 7.5$, and $5 \mathrm{~mm} \mathrm{CaCl}_{2}$ ) to extract the SDS, allowing proteins to renature within the gel. The gel was then incubated in incubation buffer (50 mM Tris- $\mathrm{HCl}, \mathrm{pH} 7.5,5 \mathrm{~mm} \mathrm{CaCl}$, and $1.25 \mu \mathrm{M} \mathrm{ZnCl}_{2}$ ) for 36-48 hr at room temperature to allow in-gel proteolytic degradation of casein. Subsequently, the gel was stained with Coomassie blue for $4 \mathrm{hr}$ and destained (10\% acetic acid and 30\% methanol) until areas of proteolysis could be visualized.

Western blot analysis. Conditioned medium from human OLs was collected after $24 \mathrm{hr}$ in culture and incubated with MMP-12 antibody bound to microbeads. Purification was performed according to the instructions of the manufacturer (MMP-12 purification kit; R \& D Systems, Minneapolis, MN). Purified protein samples were electrophoresed on $12 \%$ SDS-PAGE under reducing conditions and transferred to a polyvinylidene difluoride membrane (Millipore), which was probed for $1 \mathrm{hr}$ with a rabbit anti-MMP-12 antibody [MMP-12 (hinge); 1:3000; Chemicon]. This antibody recognizes the pro (Pro) form, the Inter form, and the active (Act) form of MMP-12. A secondary antibody (anti-rabbit HRP) was added for $1 \mathrm{hr}$, and blots were detected by enhanced chemiluminescence detection kit (Amersham Biosciences, Piscataway, NJ).

Statistical analysis. Statistical evaluation of the effect of MMP-12 function-blocking antibodies on OL process extension was performed by ANOVA with Dunnett multiple comparisons (see Fig. 3). An unpaired
A
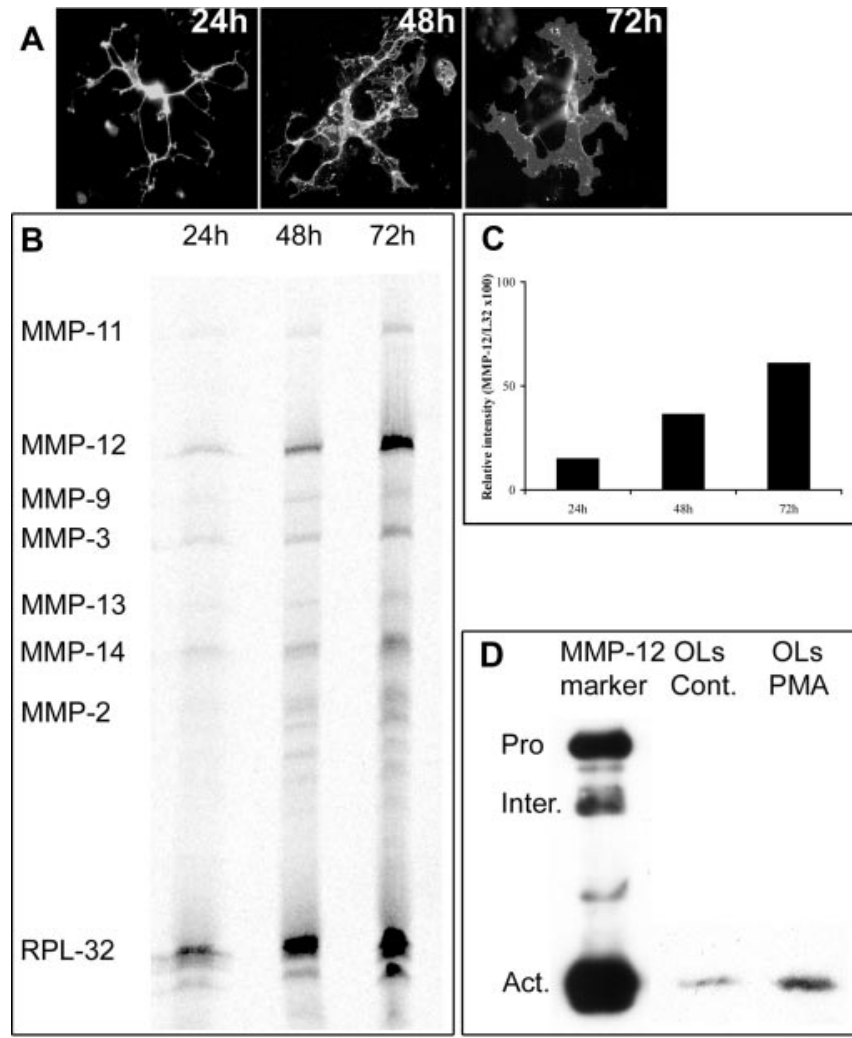

Figure 2. MMP-12 expression increases during process extension by 0 Ls. Extensive process outgrowth by murine $0 \mathrm{~L}$ lineage cells occurs between 24 and $72 \mathrm{hr}$ after plating; the processes displayed by a single cell at these time points increase in complexity during this period $(A, \operatorname{RmAb}$ immunocytochemistry). During the $24-72 \mathrm{hr}$ period of in vitro culture, RPA analysis demonstrates an increase mainly in MMP-12 expression of PMA-stimulated $0 \mathrm{Ls}(B)$. The increase in MMP-12 relative to ribosomal protein L-32 (RPL-32; loading control) is quantified in C. $\ln D$, the conditioned media of human $0 \mathrm{Ls}$, with or without PMA stimulation, were subjected to MMP-12 protein detection by Western blot analysis. Human cells were used because the MMP-12 antibody was raised to human determinants. The antibody detects the Pro, Inter, and Act forms of MMP-12. The active form was detected in basal culture, and the level of this form was increased by PMA stimulation (D). Cont., Control.

Student's $t$ test was applied to compare the means between mature OLs from wild-type and MMP-12 null mice (see Fig. 5). Similarly, Student's $t$ test was used to evaluate the morphology of OL lineage cells between wild-type and MMP-12 null mice at each classification of morphological differentiation (see Fig. 6). Error bars are all shown as SEM.

\section{Results}

Expression profiling shows MMP-12 to be highly expressed by OLs

RPA was performed on cultured glial cell populations (OLs, astrocytes, and microglia) isolated from mouse brains (Fig. $1 \mathrm{~A}$ ). Of the nine MMP members detected by RPA, MMP-12 was the most highly expressed, with increased levels seen in both OLs and microglia and lower levels detected in astrocyte cultures (Fig. $1 B$ ). Furthermore, the expression of MMP-12 transcripts could be highly induced using PMA, whereas the expression of other MMP members was minimally affected (Fig. $1 C$ ). The high level of MMP-12 expression demonstrated by RPA suggests a role for this MMP member in OL biology.

To determine whether or not MMP-12 expression correlated with OL process extension, MMP-12 transcripts were measured during the period when murine OLs extended processes in culture (Fig. 2A). MMP-12 levels were regulated in a timely manner, with transcripts increasing from 24 to $72 \mathrm{hr}$ after PMA treatment 
in culture (Fig. $2 \mathrm{~B}$ ), correlating to periods of OL process extension and the increasing complexity of the processes. The increase of MMP-12 compared with the housekeeping gene L32 was quantified by densitometry, and this confirms an increase of MMP-12 transcripts from 24 to $72 \mathrm{hr}$ in culture (Fig. 2C).

To demonstrate that the elevated MMP-12 transcripts were indeed translated into protein, MMP-12 protein expression was studied by Western blot analysis of conditioned medium from human OLs. Human cells were used because the MMP-12 antibody was raised to human MMP-12. The results show that MMP-12 protein, particularly its fully active form, was detected in human OL cultures (Fig. 2D).

In summary, these data show that MMP-12 is expressed by human and mouse OLs and that PMA increases MMP-12 expression.

Inhibition of MMP-12 activity impairs OL process extension To test the hypothesis that MMP-12 plays a role in OL process extension, human OLs were treated with MMP-12 antibodies before stimulation with PMA to promote process extension. As mentioned previously, these experiments were performed with human rather than mouse OLs because the antibodies were raised to human MMP-12 determinants. Figure 3 shows that the MMP-12 antibody targeting the N-terminal catalytic region significantly inhibited OL process extension. The MMP-12 antibody directed against the propeptide region also reduced process extension although not as markedly as the $\mathrm{N}$-terminal antibody. The antibody against the C-terminal region of MMP-12 had a slight but significant reduction of process extension, whereas no effect was seen using an antibody toward the hinge region of MMP-12 (Fig. $3 B$ ). Figure $3 A$ demonstrates the PMA promotion of process extension in human OLs $(A$, middle) and that treatment with the MMP-12 (N-term) antibody reduces the PMAinduced process extension ( $A$, right).

We next addressed whether the requirement of MMP-12 for process extension by human OLs was dependent on the time that these cells were kept unstimulated in culture. Human OLs were plated for 1, 3, or $5 \mathrm{~d}$ before MMP-12 antibodies were added. In all conditions, PMA was applied $3 \mathrm{hr}$ after the addition of the antibodies, and cells were harvested after $48 \mathrm{hr}$. The data show that the N-terminal catalytic MMP-12 antibody inhibited OL process extension even when cells were left for 3 or $5 \mathrm{~d}$ before the experiment was initiated (Fig. $4 A-C$ ). However, the potency of the function-blocking antibodies to reduce OL process extension was decreased when given to cells that had been cultured for longer periods before PMA stimulation. Again, the antibody tar-
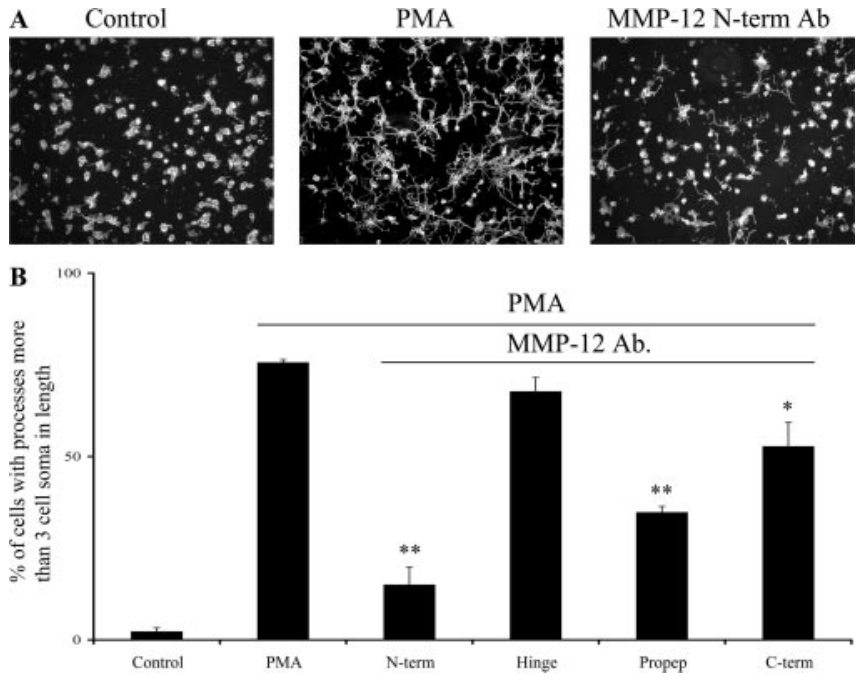

Figure 3. MMP-12 function-blocking antibodies inhibit process extension by human OLs. As described previously (Yong et al., 1991), PMA stimulation is necessary for adult human OLs to extend significant processes in vitro ( $A$, left, control condition; middle, cells treated with PMA). The PMA-induced process formation is potently inhibited by a function-blocking antibody targeted against the $\mathrm{N}$-terminal catalytic domain ( $A$, right; $B, \mathrm{~N}$-term). To a lesser degree, antibodies targeted against the propeptide domain and the $C$-terminal domain also inhibited $0 \mathrm{~L} \mathrm{pro-}$ cess extension ( $B$, Propep, $C$-term). Conversely, an antibody against the hinge region did not block $0 \mathrm{~L}$ process extension ( $B$, Hinge). ${ }^{*} p<0.05$ and ${ }^{* *} p<0.001$ compared with PMAstimulated 0 Ls with no antibody treatment.

geted against the MMP-12 hinge region did not possess functionblocking effects on OL process extension.

Previous reports have implicated MMP-9 in OL process extension (Oh et al., 1999), and concurrent data were observed in Figure 4 in which an MMP-9 function-blocking antibody reduced OL process extension resulting from PMA stimulation. However, the antibody toward the N-terminal domain of MMP-12 had more potent effects than the MMP-9-blocking antibody (Fig. 4A-C).

These observations suggest that the action of MMP-12 is to promote the initiation of process extension. After days in culture, OLs may use alternate pathways, less dependent on MMP-12 activity, to extend their processes.

\section{MMP-12 regulates the maturation of OPCs}

To examine whether MMP-12 expression was involved in the maturation of OPCs, experiments were performed using MMP-12 null
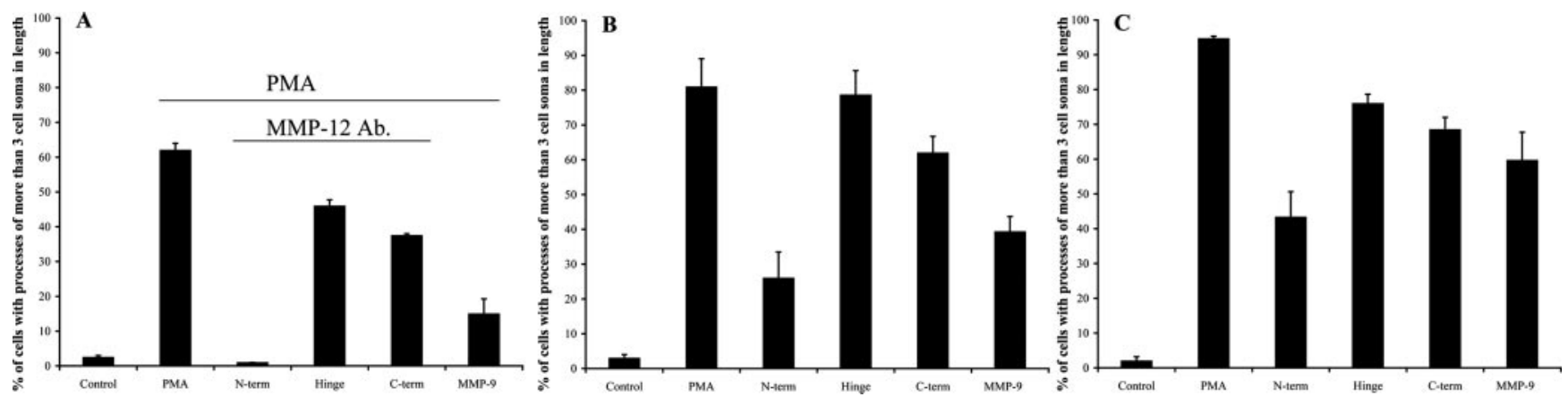

Figure 4. Time dependence of inhibition of process extension. Function-blocking antibody treatment is performed $4 \mathrm{hr}(A), 3 \mathrm{~d}(B)$, and $5 \mathrm{~d}(C)$ after the $0 \mathrm{Ls}$ are plated on poly-L-ornithine. In $A$, almost all $0 \mathrm{Ls}$ are inhibited in their ability to extend processes in the presence of MMP- 12 (N-term) antibody. This effect is reduced in $B(3 \mathrm{~d})$ and $C(5 \mathrm{~d})$. However, an $\sim 60 \%$ reduction in $0 \mathrm{~L}$ process extension is still observed in C when OLs were not treated with antibody until $5 \mathrm{~d}$ after plating. Similar to what is observed in Figure 3, the MMP-12 antibody against the hinge region did not inhibit $0 \mathrm{~L}$ process extension significantly. Furthermore, a function-blocking MMP-9 antibody shows similar trend in the temporal inhibition of process extension. In all experiments, $0 \mathrm{Ls}$ were stimulated with PMA $3 \mathrm{hr}$ after the antibodies were added. The results are normalized to the respective controls at each time period. 


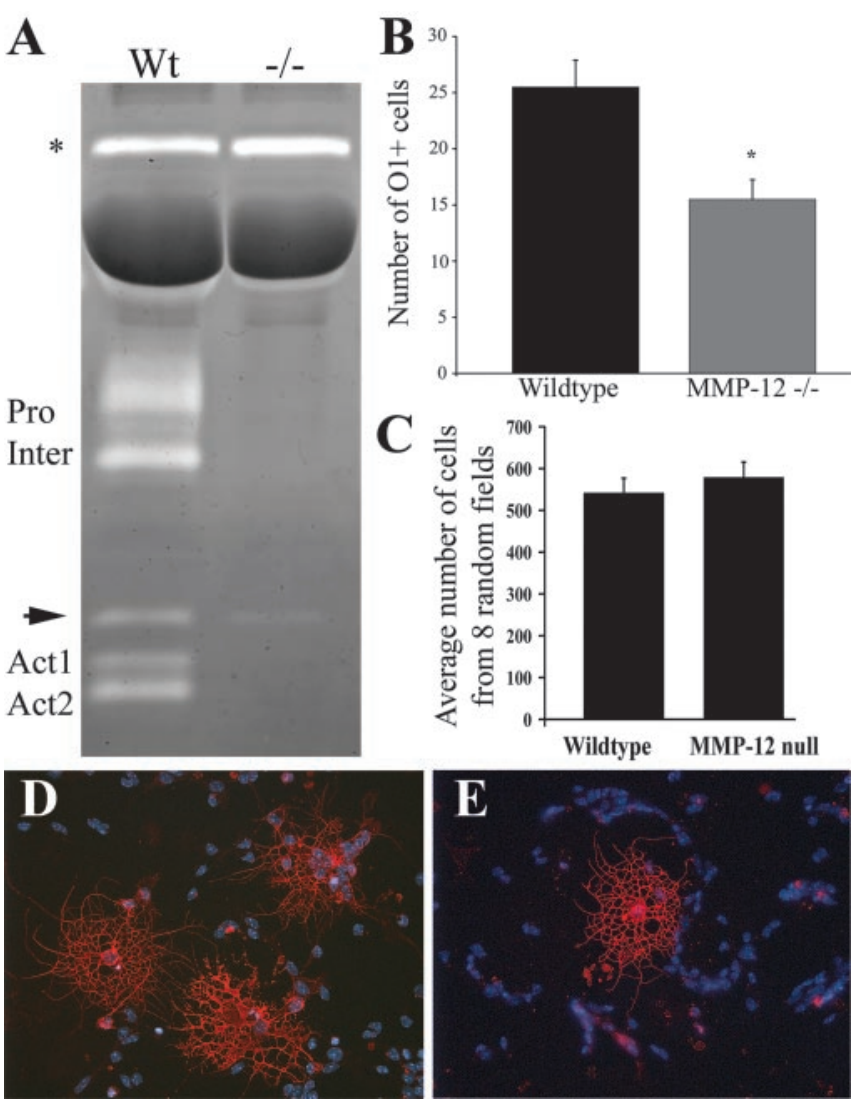

Figure 5. OL maturation is reduced in MMP-12 null mice. The lack of MMP-12 enzymatic activity in the MMP-12 null mice is verified by casein zymography of peritoneal macrophages from wild-type (Wt) or null $(-/-)$ mice $(A)$. The top proteolytic band $\left({ }^{*}\right)$ in $A$ is MMP-9, which confirms the even loading of both sets of samples. In wild-type tissue, MMP-12 gives rise to four bands (Pro, Inter, Act1, Act2). In this regard, whereas human MMP-12 has only one form of fully active MMP-12 (22 kDa), mouse MMP-12 has two fully active forms (Act1, Act2) of $\sim 25$ and 22 kDa (Janusz et al., 1999). A faint band (arrow) seen in both wild-type and MMP-12 null likely indicates proteolytic activity of MMP-7. A significant reduction (39\%) in the numbers of mature 01-positive OLs after $48 \mathrm{hr}$ differentiation of OPCs is observed in the MMP-12 null mice $(B)$. C demonstrates that a similar number of total (Hoechst positive) cells are present in both genotypes. Representative pictures show mature 01-positive cells from wild-type (D) and MMP-12 null mice $(E) .{ }^{*} p<0.05$.

mice. Casein zymography was used to verify that MMP-12 activity was completely absent in these animals (Fig. 5A). The faint band seen in both the wild-type and the MMP-12 null lane is possibly MMP-7, which is also detected by casein zymography (Fig. 5A, arrow) (Yu and Woessner, 2001).

OPCs were isolated by A2B5 immunomagnetic sorting from wild-type and MMP-12 null mice, and their ability to differentiate into process-bearing galactocerebroside-positive mature OLs (using the $\mathrm{O} 1$ antibody) was compared. After $48 \mathrm{hr}$ of maturation in culture, the number of $\mathrm{O}^{+}$cells was counted in the two genotypes. The data in Figure $5 B$ represent the average number of $\mathrm{O}^{+}{ }^{+}$cells in four wells for each genotype. A significant reduction $(39 \%)$ in the number of mature OLs was observed in mice lacking MMP-12 activity (Fig. 5B). To exclude the possibility of excessive cell death in the cultures from MMP-12 null mice, the total number of cells in eight random fields was compared between the two genotypes (Fig. 5C). No differences in total cell numbers were observed between the two genotypes.

Overall, the maturation of OPCs into OLs was decreased but not abolished by the absence of MMP-12, suggesting a role for MMP-12 in the maturation process.

\section{MMP-12 regulates morphological differentiation of OL} lineage cells

In parallel studies to the maturation experiments, we investigated whether there was a deficit in the morphological differentiation of OL lineage cells. As noted previously, cells were immunolabeled with RmAb to detect both immature and mature cells of the OL lineage to allow for characterization of all OL lineage cells at different stages of process extension. Examples of cells classified into different stages of morphological differentiation are displayed in Figure $6 \mathrm{~A}$. All morphological examinations were performed under blinded conditions.

Cultures of purified wild-type and MMP-12 null cells were examined $48 \mathrm{hr}$ after plating. Significantly fewer cells with lowmed, med-high, and high morphologies were detected in cultures from MMP-12 null mice (Fig. $6 B$ ) compared with wild-type cells. Conversely, there were significantly increased numbers of cells with low morphology in the MMP-12 null mice (Fig. $6 \mathrm{~B}$ ).

The suggestion that MMP-12 regulates morphological differentiation was further tested using an MMP-12 function-blocking antibody. We found that the differentiation of wild-type cells to the low-med, med-high, and high morphologies was significantly inhibited by the addition of MMP-12 function-blocking antibody (Fig. 6C). In addition, a significantly larger proportion of cells remained as cells with low morphology. Finally, exogenous purified MMP-12 was applied to cultures of MMP-12 null animals, and this resulted in an increase in the number of cells with low-med, med-high, and high morphologies that approaches wild-type levels (Fig. 6D). In conjunction, the less morphologically mature OL lineage cells decreased in numbers, suggesting that immature cells were converted to morphologically more differentiated forms (Fig. 6D).

These murine data, along with the process extension results using human OLs described previously (Fig. 3), support a role for MMP-12 in controlling the morphological differentiation of cells of the OL lineage.

\section{Discussion}

This work has addressed the functional importance of MMP-12 activity for OL development. In recent years, metalloproteinase activity has been correlated with many aspects of development. Examples include the observations that angiogenesis (Canete Soler et al., 1995a; Vu et al., 1998; Werb et al., 1999) and the migration of neuronal precursor cells and OPCs (Amberger et al., 1997; Vaillant et al., 2003) seem to require metalloproteinase activity. A growing list has ascribed novel functions of metalloproteinases in normal development, such as in cytokine activation-inactivation and controlling apoptotic pathways (for review, see Sternlicht and Werb, 2001). These findings have left us with a more complex picture of the functional roles metalloproteinases have in different cell types during developmental processes.

In this study, we investigated the role of MMP-12 in OL biology, prompted by the finding that MMP-12 transcripts were produced in high amounts by OLs in culture (Fig. 1). We also found MMP-12 in microglia, which is not surprising because MMP-12 is reported in cells of monocytoid lineage (Shapiro et al., 1993). Indeed, this is the first description of MMP-12 in OLs and one of the very few to place MMP-12 expression outside of cells of the monocytoid lineage.

We showed previously that MMP-9 is important for OL process extension and myelin development, and the finding that MMP-12 is expressed by OLs prompted us to investigate similar functions for MMP-12. We first tested the effects of functionblocking antibodies to MMP-12 on OL process outgrowth. Three antibodies targeted against different domains of MMP-12 dem- 

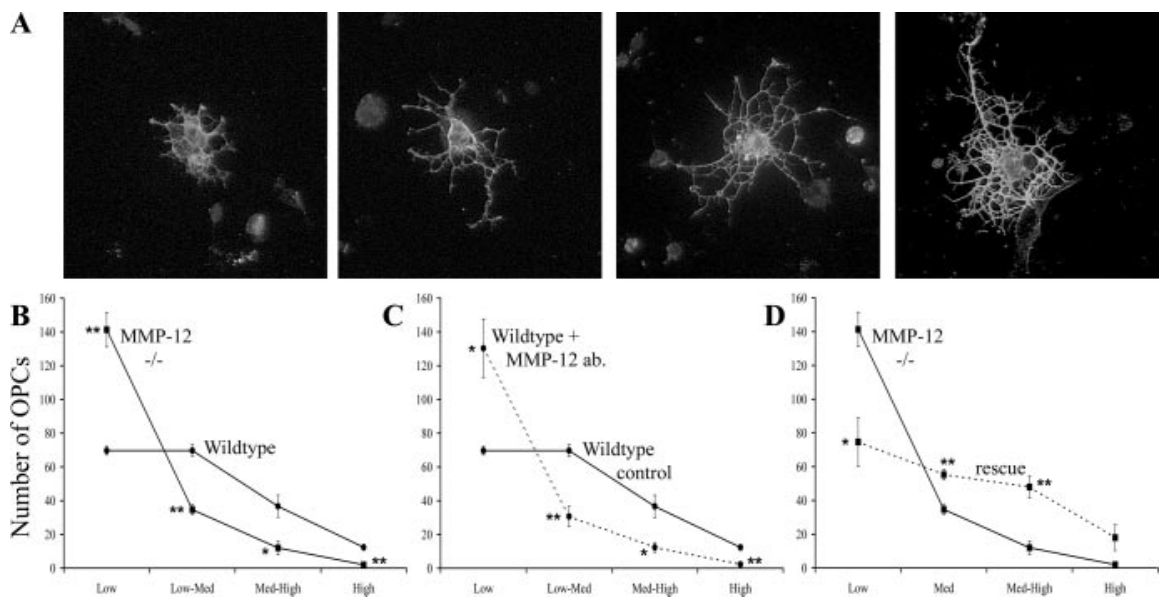

Figure 6. Reduced morphological differentiation in the absence of MMP-12. Representative pictures of four different morphological stages of development of $\mathrm{RmAb}^{+} \mathrm{OL}$ lineage cells are shown in $A$. During differentiation, cells become morphologically more complex ( $A$, left to right, representing cells with processes of low, low-med, med-high, and high morphology, respectively). In $A$, the morphological complexity revealed by immunohistochemistry was also seen in corresponding phase-contrast micrographs (data not shown), supporting that there was a real membrane change rather than an alteration in the localization of the antigen. Cells from MMP-12 null mice show a higher number of cells with low morphologies and fewer cells with low-med, med-high, and high morphologies compared with that of wild-type mice ( $B$ ). A function-blocking MMP-12 (N-term) antibody converts wild-type cells (solid line) into a MMP-12 null morphological phenotype (dotted line), as fewer cells reach a morphologically more mature stage (C). Furthermore, rescue experiments show that MMP-12 null cells (solid line) become morphologically more mature (dotted line) after the exogenous addition of purified MMP-12 protein ( $D$ ). All graphs show the average number of cells per entire well for three wells in each group. Experiments were repeated three times with congruent results. ${ }^{*} p<0.05$; ${ }^{* *} p<0.001$.

onstrated function-blocking effects, and PMA-induced OL process extension was significantly reduced (Fig. 3). A fourth antibody raised against the hinge region did not show any blocking effects. One possible explanation for the various inhibitory effects between the different MMP-12 antibodies may be the different domains to which they bind. It is likely that the antibody binding to the hinge region of MMP-12 (which is not a true part of the catalytic domain) did not interfere with the activity of this enzyme, whereas antibodies interacting at the catalytic site and propeptide regions hindered correct activation of this enzyme, resulting in the observed functional blockage of OL process extension. An antibody to the $\mathrm{C}$ terminus of MMP-12 also reduced process extension, which could be the result of interfering with the binding of MMP-12 to its substrate because C termini of MMPs are involved in substrate binding (Overall, 2002).

Additional evidence for MMP-12 in process extension comes from a blinded analysis of OL lineage cells with different morphological complexities. We found significantly fewer OL lineage cells with highly branched processes in the MMP-12 null cultures compared with wild-type cells (Fig. $6 \mathrm{~B}$ ). In correspondence, blocking MMP-12 of wild-type cells reduced their differentiation, whereas MMP-12 added exogenously to MMP-12 null cells enabled morphological differentiation (Fig. 6C,D). Future experiments will determine whether manipulating MMP-9 also have similar effects.

We also investigated a role for MMP-12 in OL maturation by examining the number of mature $\mathrm{O} 1{ }^{+}$OLs present after $48 \mathrm{hr}$ in A2B5-sorted cultures (Fig. 5). There was an $\sim 40 \%$ reduction in the number of $\mathrm{O}^{+}$cells in the MMP-12 null cultures compared with wild-type ones, suggesting that MMP-12 plays a role in the timely maturation of OLs.

Although the substrate that is processed by MMP-12 to promote differentiation and maturation of OLs is not known, possible candidates include neuregulin, insulin-like growth factor-1 (IGF-1), or IGF binding proteins and thyroid hormone, which

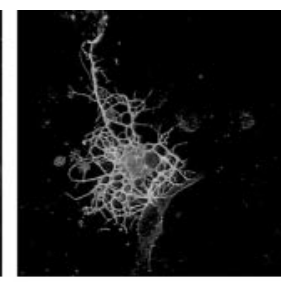

are all involved in OPC development (D'Ercole et al., 1996; Rodriguez-Pena, 1999; Fernandez et al., 2000; Kuhl et al., 2003). Many other molecular pathways have been described to be involved in OPC maturation and for myelin formation. For example, the Notch pathway has been found to both inhibit and promote OPC maturation depending on the activating ligand for Notch (Wang et al., 1998; Hu et al., 2003). Two metalloproteinases, ADAM (a disintegrin and metalloprotease) -10 and -17 , have been proposed to cleave Notch (Pan and Rubin, 1997; Brou et al., 2000). Thus, it is possible that MMP12 , in concert with other metalloproteinases, could be responsible for regulating the activity of the Notch pathway in OL biology.

MMP-12 is able to cleave a variety of extracellular molecules and growth factors in vitro, and this may also account for the MMP-12 activity in OPC differentiation and maturation. Additional investigation of the role and substrates of MMP-12 in developmental myelination is required.

Previous reports have mostly focused on the role of MMP-12 in macrophages in which it is highly expressed. This study shows for the first time that MMP-12 is expressed in CNS glia cells in which it plays a role in OL maturation and process extension. The lack of MMP-12 could have profound effects on developmental myelination if the maturation of OLs is delayed. However, it is possible that other metalloproteinases have redundant effects and can substitute for the lack of MMP-12 activity as a result of their broad substrate specificity. In this regard, MMP-9 has been implicated previously in OL process extension and increases early during developmental myelination (Uhm et al., 1998; Oh et al., 1999). The finding that MMP-12 null OLs still mature, although in lower numbers, suggests that MMP-12 is not the only MMP member capable of driving this event.

In conclusion, we have identified an MMP member that is being highly expressed in OLs. With respect to a functional role, this study implicates MMP-12 activity in the control of morphological differentiation (process extension) and maturation of cells of the OL lineage.

\section{References}

Amberger VR, Avellana-Adalid V, Hensel T, Baron-van Evercooren A, Schwab ME (1997) Oligodendrocyte-type 2 astrocyte progenitors use a metalloendoprotease to spread and migrate on CNS myelin. Eur J Neurosci 9:151-162.

Annabi B, Shedid D, Ghosn P, Kenigsberg RL, Desrosiers RR, Bojanowski MW, Beaulieu E, Nassif E, Moumdjian R, Beliveau R (2002) Differential regulation of matrix metalloproteinase activities in abdominal aortic aneurysms. J Vasc Surg 35:539-546.

Bansal R, Warrington AE, Gard AL, Ranscht B, Pfeiffer SE (1989) Multiple and novel specificities of monoclonal antibodies O1, O4, and R-mAb used in the analysis of oligodendrocyte development. J Neurosci Res 24:548-557.

Brou C, Logeat F, Gupta N, Bessia C, LeBail O, Doedens JR, Cumano A, Roux P, Black RA, Israel A (2000) A novel proteolytic cleavage involved in Notch signaling: the role of the disintegrin-metalloprotease TACE. Mol Cell 5:207-216.

Canete Soler R, Gui YH, Linask KK, Muschel RJ (1995a) MMP-9 (gelatinase 
B) mRNA is expressed during mouse neurogenesis and may be associated with vascularization. Brain Res Dev Brain Res 88:37-52.

Canete-Soler R, Gui YH, Linask KK, Muschel RJ (1995b) Developmental expression of MMP-9 (gelatinase B) mRNA in mouse embryos. Dev Dyn 204:30-40.

Corley SM, Ladiwala U, Besson A, Yong VW (2001) Astrocytes attenuate oligodendrocyte death in vitro through an alpha(6) integrin-laminindependent mechanism. Glia 36:281-294.

D'Ercole AJ, Ye P, Calikoglu AS, Gutierrez-Ospina G (1996) The role of the insulin-like growth factors in the central nervous system. Mol Neurobiol 13:227-255.

Eisenbarth GS, Walsh FS, Nirenberg M (1979) Monoclonal antibody to a plasma membrane antigen of neurons. Proc Natl Acad Sci USA 76:4913-4917.

Fernandez PA, Tang DG, Cheng L, Prochiantz A, Mudge AW, Raff MC (2000) Evidence that axon-derived neuregulin promotes oligodendrocyte survival in the developing rat optic nerve. Neuron 28:81-90.

Hu QD, Ang BT, Karsak M, Hu WP, Cui XY, Duka T, Takeda Y, Chia W, Sankar N, Ng YK, Ling EA, Maciag T, Small D, Trifonova R, Kopan R, Okano H, Nakafuku M, Chiba S, Hirai H, Aster JC, Schachner M, Pallen CJ, Watanabe K, Xiao ZC (2003) F3/contactin acts as a functional ligand for Notch during oligodendrocyte maturation. Cell 115:163-175.

Janusz MJ, Hare M, Durham SL, Potempa J, McGraw W, Pike R, Travis J, Shapiro SD (1999) Cartilage proteoglycan degradation by a mouse transformed macrophage cell line is mediated by macrophage metalloelastase. Inflamm Res 48:280-288.

Kuhl NM, Hoekstra D, De Vries H, De Keyser J (2003) Insulin-like growth factor-binding protein 6 inhibits survival and differentiation of rat oligodendrocyte precursor cells. Glia 44:91-101.

Lanone S, Zheng T, Zhu Z, Liu W, Lee CG, Ma B, Chen Q, Homer RJ, Wang J, Rabach LA, Rabach ME, Shipley JM, Shapiro SD, Senior RM, Elias JA (2002) Overlapping and enzyme-specific contributions of matrix metalloproteinases-9 and -12 in IL-13-induced inflammation and remodeling. J Clin Invest 110:463-474.

Larsen PH, Wells JE, Stallcup WB, Opdenakker G, Yong VW (2003) Matrix metalloproteinase- 9 facilitates remyelination in part by processing the inhibitory NG2 proteoglycan. J Neurosci 23:11127-11135.

Matsumoto S, Kobayashi T, Katoh M, Saito S, Ikeda Y, Kobori M, Masuho Y, Watanabe T (1998) Expression and localization of matrix metalloproteinase-12 in the aorta of cholesterol-fed rabbits: relationship to lesion development. Am J Pathol 153:109-119.

Oh LY, Larsen PH, Krekoski CA, Edwards DR, Donovan F, Werb Z, Yong VW (1999) Matrix metalloproteinase-9/gelatinase B is required for process outgrowth by oligodendrocytes. J Neurosci 19:8464-8475.

Overall CM (2002) Molecular determinants of metalloproteinase substrate specificity: matrix metalloproteinase substrate binding domains, modules, and exosites. Mol Biotechnol 22:51-86.

Pagenstecher A, Stalder AK, Kincaid CL, Shapiro SD, Campbell IL (1998) Differential expression of matrix metalloproteinase and tissue inhibitor of matrix metalloproteinase genes in the mouse central nervous system in normal and inflammatory states. Am J Pathol 152:729-741.

Pan D, Rubin GM (1997) Kuzbanian controls proteolytic processing of Notch and mediates lateral inhibition during Drosophila and vertebrate neurogenesis. Cell 90:271-280.
Ranscht B, Clapshaw PA, Price J, Noble M, Seifert W (1982) Development of oligodendrocytes and Schwann cells studied with a monoclonal antibody against galactocerebroside. Proc Natl Acad Sci USA 79:2709-2713.

Rodriguez-Pena A (1999) Oligodendrocyte development and thyroid hormone. J Neurobiol 40:497-512.

Sekine-Aizawa Y, Hama E, Watanabe K, Tsubuki S, Kanai-Azuma M, Kanai Y, Arai H, Aizawa H, Iwata N, Saido TC (2001) Matrix metalloproteinase (MMP) system in brain: identification and characterization of brainspecific MMP highly expressed in cerebellum. Eur J Neurosci 13:935-948.

Shapiro SD, Kobayashi DK, Ley TJ (1993) Cloning and characterization of a unique elastolytic metalloproteinase produced by human alveolar macrophages. J Biol Chem 268:23824-23829.

Shipley JM, Wesselschmidt RL, Kobayashi DK, Ley TJ, Shapiro SD (1996) Metalloelastase is required for macrophage-mediated proteolysis and matrix invasion in mice. Proc Natl Acad Sci USA 93:3942-3946.

Sommer I, Schachner M (1981) Monoclonal antibodies (O1 to O4) to oligodendrocyte cell surfaces: an immunocytological study in the central nervous system. Dev Biol 83:311-327.

Sternlicht MD, Werb Z (2001) How matrix metalloproteinases regulate cell behavior. Annu Rev Cell Dev Biol 17:463-516.

Uhm JH, Dooley NP, Oh LY, Yong VW (1998) Oligodendrocytes utilize a matrix metalloproteinase, MMP-9, to extend processes along an astrocyte extracellular matrix. Glia 22:53-63.

Vaillant C, Didier-Bazes M, Hutter A, Belin MF, Thomasset N (1999) Spatiotemporal expression patterns of metalloproteinases and their inhibitors in the postnatal developing rat cerebellum. J Neurosci 19:4994-5004.

Vaillant C, Meissirel C, Mutin M, Belin MF, Lund LR, Thomasset N (2003) MMP-9 deficiency affects axonal outgrowth, migration, and apoptosis in the developing cerebellum. Mol Cell Neurosci 24:395-408.

Vos CM, van Haastert ES, de Groot CJ, van der Valk P, de Vries HE (2003) Matrix metalloproteinase-12 is expressed in phagocytotic macrophages in active multiple sclerosis lesions. J Neuroimmunol 138:106-114.

Vu TH, Shipley JM, Bergers G, Berger JE, Helms JA, Hanahan D, Shapiro SD, Senior RM, Werb Z (1998) MMP-9/gelatinase B is a key regulator of growth plate angiogenesis and apoptosis of hypertrophic chondrocytes. Cell 93:411-422.

Wang S, Sdrulla AD, diSibio G, Bush G, Nofziger D, Hicks C, Weinmaster G, Barres BA (1998) Notch receptor activation inhibits oligodendrocyte differentiation. Neuron 21:63-75.

Webber CA, Hocking JC, Yong VW, Stange CL, McFarlane S (2002) Metalloproteases and guidance of retinal axons in the developing visual system. J Neurosci 22:8091-8100.

Werb Z, Vu TH, Rinkenberger JL, Coussens LM (1999) Matrix-degrading proteases and angiogenesis during development and tumor formation. APMIS 107:11-18.

Yong VW, Cheung JC, Uhm JH, Kim SU (1991) Age-dependent decrease of process formation by cultured oligodendrocytes is augmented by protein kinase C stimulation. J Neurosci Res 29:87-99.

Yu WH, Woessner Jr JF (2001) Heparin-enhanced zymographic detection of matrilysin and collagenases. Anal Biochem 293:38-42.

Zuo J, Ferguson TA, Hernandez YJ, Stetler-Stevenson WG, Muir D (1998) Neuronal matrix metalloproteinase-2 degrades and inactivates a neuriteinhibiting chondroitin sulfate proteoglycan. J Neurosci 18:5203-5211. 